\title{
Equivalence in Translation
}

\author{
Ali Reza Ghanooni \\ Yerevan State University
}

\begin{abstract}
$\mathrm{T}$ he prevalent concept in the 1950s for most translation theory is equivalence. Translating is generally seen as a process of communicating the foreign text by establishing a relationship of identity or analogy with it. Equivalence can be said to be the central issue in translation although its definition, relevance, and applicability within the field of translation theory have caused heated controversy, and many different theories of the concept of equivalence have been elaborated within this field in the past fifty years. Approaches to the question of equivalence differ radically. Theorists as Catford (1965), Nida \& Taber (1969) and Koller (1995), define translation in terms of equivalence relations, while others, such as Snell-Hornby (1988) reject the theoretical notion of equivalence, holding that it is either irrelevant or damaging to translation studies. However, Baker (1992) adopts a middle course, using this notion for the sake of convenience because most translators are used to it rather than because it has any theoretical status. Those in favor of equivalence-based theories of translation define equivalence as the relationship between a source-text and a target text that allows the TT to be deemed as a translation of the ST in the first place. Theorists who maintain that translation is contingent upon equivalence, have attempted to develop typologies of equivalence, either focusing on the rank (word, sentence, text) at which level equivalence is said to obtain, or on the type of meaning (denotative, connotative, pragmatic, etc.) (Baker 1997). In this article the viewpoints of translation scholars as regards "equivalence" will be taken into account. These theorists have studied equivalence in relation to translation process, using different approaches.

Roman Jackobson (1959) is a figure who theorizes about equivalence. His study of equivalence gave new impetus to the theoretical analysis of translation since he introduced the notion of "equivalence in difference". On the basis of his semiotic approach to language and his aphorism "there is no signatum without signum" (1959:232), he suggests three kinds of translation:

- Intralingual (within one language, i.e. rewording or paraphrasing)

- Interlingual (between two languages or translation proper)

- Intersemiotic (between sign systems or transmutation)

He goes on to examine the key issues of translation, notably, linguistic meaning and equivalence. He considers the problem of equivalence in meaning between words in different languages. According to him (1959:114), there is no full equivalence between code-units. In his description, interlingual translation involves substituting messages in one language not for separate code-units but for entire messages in some other language. The translation involves two equivalent messages in two different codes. An example he gives is that of cheese in English, which is not identical to the Russian word syr, since the Russian code-unit does not include the concept of cottage cheese, therefore, the best way is to expand the word in the TL. He acknowledges that "whenever there is deficien-
\end{abstract}


cy, terminology may be qualified and amplified by loanwords or loan-translations, neologisms or semantic shifts, and finally, by circumlocutions".

It can be concluded that Jakobson's theory is essentially based on his semiotic approach to translation according to which the translator has to recode the ST message first and then she/he has to transmit it into an equivalent message for the TC.

Vinay and Darbelnet (2000:83-93, quoted in Munday, 2001) identify two translation strategies, "direct translation and oblique translation". Borrowing, calque and literal translation procedures are the procedures used for direct translation in cases where the items pose no real problem and can be easily relayed. However, there are cases in which literal translation is not possible and, for this reason, the translator should avail himself of "oblique translation". It includes "transposition, modulation, equivalence and adaptation".

Vinay and Darbelnet view equivalence-oriented translation as a procedure which "replicates the same situation as in the original, whilst using completely different wording" (ibid.:90). They also suggest that if this procedure is applied during the translation process, it can maintain the stylistic impact of the SL text in the TL text. According to them, equivalence is therefore the ideal method when the translator has to deal with proverbs, idioms, clichés, nominal or adjectival phrases and the onomatopoeia of animal sounds.

Catford's approach to translation equivalence clearly differs from that adopted by Nida: Catford had a preference for a more linguistic-based approach to translation and this approach is based on the ideas put forward by Firth and Halliday. The latter treat language as communication that operates functionally in context and on a range of different levels (e.g. phonology, graphology, lexis, grammar) and ranks (sentence, clause, group, word, morpheme).

Catford proposed very broad types of translation in terms of three criteria:

1. The extent of translation (full translation vs partial translation);

2. The grammatical rank at which the translation equivalence is established (rank-bound translation vs. unbounded translation);

3. The levels of language involved in translation (total translation vs. restricted translation).

In this article the second type of translation will be referred to, since it concerns the concept of equivalence. We will then move on to analyze the notion of translation shifts, as elaborated by Catford which are based on the distinction between formal correspondence and textual equivalence. In rank-bound translation an equivalent is sought in the TL for each word, or for each morpheme encountered in the ST. In unbounded translation equivalences are not tied to a particular rank, and we may additionally find equivalences at the levels of the sentence, the clause etc.

Catford makes a distinction between "formal correspondence" and "textual equivalence". In this dichotomy the former is "any TL category (unit, class, element of structure, etc.) which can be said to occupy the same place in the economy of the TL as the given SL category occupies in the SL" (Catford 1965:27).

The latter is "any text or portion of text which is observed on a particular occasion to be the equivalent of a given SL text or portion of text".

Translation theorists who privilege equivalence must inevitably come to terms with 
the existence of "shifts" between foreign and translated texts. Catford defines them as "departures from formal correspondence in the process of going from the SL to the TL" (ibid.:73). Catford argues that there are two main types of translation shifts, namely level shifts, where the SL item at one linguistic level (e.g. grammar) has a TL equivalent at a different level (e.g. lexis), and category shifts which are divided into four types:

Structure-shifts, which involve a grammatical change between the structure of the ST and that of the TT;

Class-shifts, when a SL item is translated with a TL item which belongs to a different grammatical class, i.e. a verb may be translated with a noun;

Unit-shifts, which involve changes in rank;

Intra-system shifts, which occur when "SL and TL possess systems which approximately correspond formally as to their constitution, but when translation involves selection of a non-corresponding term in the TL system" (ibid.:80). For instance, when the SL singular becomes a TL plural.

Finally, Catford comes to the conclusion that "translation equivalence does not entirely match formal correspondence". However, Catford was criticised for his linguistic theory of translation. The translation process cannot simply be reduced to a linguistic exercise, as claimed by Catford, for instance, since there are also other factors, such as textual, cultural and situational aspects which should be taken into consideration when translating. In other words, Snell-Hornby (1988) does not believe that linguistics is the only discipline which enables people to carry out a translation, since translating involves different cultures and different situations at the same time and they do not always match in the languages under question.

As might be imagined, scholars working in non-linguistic translation studies have been critical of the notion of equivalence. Bassnett (1980:25) summarises the major problems as she sees it: "Translation involves far more than replacement of lexical and grammatical items between languages. Once the translator moves away from close linguistic equivalence, the problems of determining the exact nature of the level of equivalence aimed for begin to emerge".

For Nida (1964a:159), there are two types of equivalence: "formal equivalence" and "dynamic equivalence". The former focuses attention on the message itself, in both form and content. One is concerned that the message in the receptor language should match as closely as possible the different elements in the source language. It is oriented towards the ST structure. Typical of this kind of translation is "gloss translation", with profuse footnotes, allowing the reader to gain close access to the language and customs of the source culture. On the other hand, "dynamic equivalence" is based on "the principle of equivalent effect", where the relationship between receptor and message should be the same as that which existed between the original receptors and the message. They argue that "Frequently, the form of the original text is changed; but as long as the change follows the rules of back transformation in the 
source language, of contextual consistency in the transfer, and of transformation in the receptor language, the message is preserved and the translation is faithful" (Nida and Taber 1969:200).

For Nida, the success of the translation depends on achieving equivalent response with four requirements: making sense, conveying the spirit and manner of the original, having a natural and easy form and producing similar response.

In order to answer the question "what exactly has to be equivalent", Koller (1979a:186) describes five types of equivalence:

1. Denotative equivalence: the SL and TL words refer to the same thing in the real world. He calls it "content invariance".

2. Connotative equivalence: the SL and TL words trigger the same or similar associations in the minds of the native speakers of the two languages. It is related to the lexical choices, especially between near synonyms. Koller sees this as "stylistic equivalence".

3. Text-normative equivalence: This is pertinent with text-types, with different kinds of texts behaving in different ways. This is closely linked to work by Catharina Reiss who classifies the text as informative, expressive and operative.

4- Pragmatic equivalence: This type is oriented towards the receptor language reader, called "communicative equivalence". This is Nida's dynamic equivalence.

5. Formal equivalence: This is related to the form and the aesthetics of the text, including the stylistic features of the ST.

However, Baker (1992) puts together the linguistic and the communicative approach. She puts a distinction between equivalence in translation that can appear at word level and above word level. Baker acknowledges that in the bottom-up approach to translation equivalence at word level is the first element to be taken into consideration by the translator. In fact, when the translator starts analyzing the ST she/he looks at the words as single units in order to find a direct "equivalent" term in the TL. Baker gives a definition of the term word, since it should be remembered that a single word can sometimes be assigned different meanings in different languages and might be regarded as being a more complex unit or morpheme. This means that the translator should pay attention to a number of factors when considering a single word, such as number, gender and tense (ibid.:11-12).

When referring to the diversity of grammatical categories across languages, she speaks about grammatical equivalence. She states that grammatical rules may vary across languages and this may pose some problems in terms of finding a direct correspondence in the TL. In fact, she claims that different grammatical structures in the SL and TL may cause remarkable changes in the way the information or message is carried across. These changes may induce the translator either to add or to omit information in the TT because of the lack of particular grammatical devices in the TL itself. Amongst these grammatical devices which might cause problems in translation, Baker focuses on number, tense and aspect, voice, person and gender.

Textual equivalence is referred to when discussing the equivalence between a SL text and a TL text in terms of information and cohesion. Texture is a very important feature 
in translation since it provides useful guidelines for the comprehension and analysis of the ST which can help the translator in his or her attempt to produce a cohesive and coherent text for the TC audience in a specific context. It is up to the translator to decide whether or not to maintain the cohesive ties as well as the coherence of the SL text. His or her decision will be guided by three main factors, that is, the target audience, the purpose of the translation and the text type.

Pragmatic equivalence is referred to in connection with implicatures and strategies of avoidance during the translation process. Implicature is information which is not said explicitly but is implied. Therefore, the translator needs to work out implied meanings in translation in order to get the ST message across. The role of the translator is to recreate the author's intention in another culture in such a way that enables the TC reader to understand it clearly.

To sum up, the concept of equivalence is very vague, encompassing diverse points of view, not enjoying a unique base to place the translation on. For this reason, this concept has lost color and popularity. In general, these theories can be divided into three categories. A group of translation scholars are in favour of a linguistic approach to translation, considering translation as merely a matter of linguistics. However, the translator is also dealing with two different cultures at the same time. This particular aspect seems to have been taken into consideration by another group of theorists who regard translation equivalence as being essentially a transfer of the message and a pragmatic/functionally oriented approach to translation. Finally, there are other translation scholars who seem to stand in the middle, such as Baker for instance, who claims that equivalence is used "for the sake of convenience - because most translators are used to it rather than because it has any theoretical status".

\section{References:}

1. Baker, M. (1992) In Other Words: a Coursebook on Translation. London: Routledge.

2. Baker, M. (1997) The Routelege Encyclopedia of Translation Studies. London and New York: Routlege.

3. Bassnett, S. (1980) Translation Studies. London and New York: Routledge.

4. Catford, J.C. (1965) A Linguistic Theory of Translation: an Essay on Applied Linguistics. London: Oxford University Press.

5. Jakobson, R. (1959) On Linguistic Aspects of Translation. // On Translation. / Ed. by R.A. Brower. Cambridge. MA: Harvard University Press.

6. Koller, W. (1979a) Einführung in die Übersetyungswissenschaft. HeidelbergWiesbaden: Quelle und Mezer, The English translation of the chapter appears in A. Chesterman (Ed.) (1989).

7. Nida, E. (1964) Towards a Science of Translating. Leiden: E. J. Brill.

8. Nida, E. and Taber, C.R (1969/1982) The Theory and Practice of Translation. Leiden: E. J. Brill. 
9. Snell-Hornby, M. (1988) Translation Studies: An Integrated Approach. Amsterdam: Benjamins.

10. Vinay, J.P. and Darbelnet, J. (1995) Comparative Stylistics of French and English: a Methodology for Translation. / Tr. by J.C. Sager and M.J. Hamel. Amsterdam / Philadelphia: John Benjamins.

\section{مupquiufinıpjufi hư์updtpnıpjnıfip}

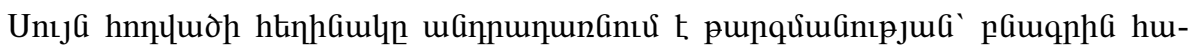

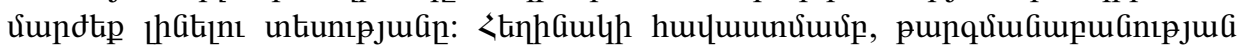

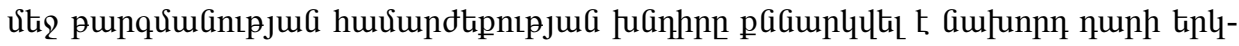

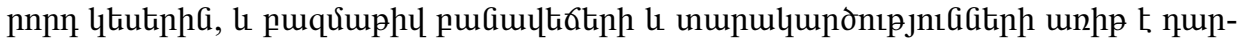

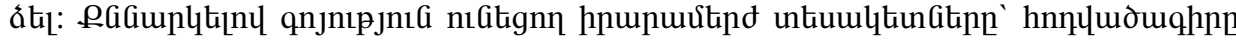

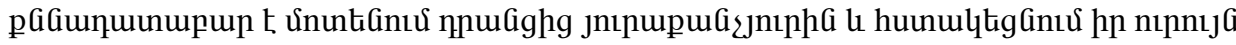
ununtigntúp pGieunluln hunghG: 